\title{
PAULINA SIKORA-KRIZHEVSKA
}

(iD) https://orcid.org/0000-0003-1395-7912

Uniwersytet Łódzki

Wydział Filologiczny

Instytut Rusycystyki

Katedra Literatury i Kultury Rosyjskiej

90-226 Łódź

ul. Pomorska 171/173

paulina.sikora@uni.lodz.pl

\section{ИГРА С ДРАМАТУРГИЧЕСКИМИ ТРАДИЦИЯМИ В ПЬЕСЕ АННЫ КАШИНОЙ ДУМА}

\section{PLAYING WITH THE DRAMATURGICAL TRADITION IN ANNA KASHINA'S PLAY DUMA}

\begin{abstract}
В статье анализируется сочетание классических и новаторских художественных приемов в пьесе Анны Кашиной Дума. Описывается игра с драматургической традицией, осуществляющаяся на уровнях: системы персонажей, изложенного в ремарках изобразительного ряда (введения видеопроекций, перенесения действия в зрительный зал), а также композиции произведения. Автор рассматривает пьесу А. Кашиной как произведение, поэтика которого детерминирована как эстетикой современных визуальных медиа, так и литературной традицией.
\end{abstract}

Ключевые слова: игра с традицией, Анна Кашина, современная драма, повествователь, проекция.

The article deals with the combination of classical and innovative artistic techniques in the play Duma by Anna Kashina. Playing with the dramaturgical tradition on different levels is described and it is shown to embrace the system of characters, the content of the stage directions (the insertion of video projections, moving the action to auditorium) and also the composition of the play. Kashina's play is discussed by the author as a work whose poetics is determined by the aesthetics of modern visual media as well as by the literary tradition.

Keywords: playing with tradition, Anna Kashina, contemporary drama, narrator, video art.

Драматургия XXI века, при всей своей экспериментальности и порой радикальном поиске новых форм и языка, не отказалась от диалога с традицией. Диалог этот может проявляться самыми разными способами: часть авторов по-новому подает «вечные» традиционные проблемы (Ирина Васьковская, 
Уроки сердиа), другие используют ремейковые стратегии, перерабатывая классические произведения (Михаил Угаров Смерть Ильи Ильчча) или цитируют писателей-классиков (Сергей Решетников, Часовой). Бывают также и те, чьи тексты, на первый взгляд порывающие с классическими принципами, на уровне поэтики все же частично следуют драматургической традиции, «играя» с ней и создавая новый пласт значений в произведении.

Под понятием «игры с драматургической традицией» имеются здесь в виду художественные приемы, предусматривающие такой способ диалога с культурно-художественным опытом прошлых веков, который обманывает ожидания привыкшего к классическому канону читателя ${ }^{1}$ и не отвечает устоявшимся в течение столетий правилам создания драматического произведения, а также сочетание элементов разных эстетических и поэтических систем, применяемое в поиске новых драматургических средств. Вышеупомянутый способ обращения с литературной традицией представлен в пьесе Анны Кашиной Дума.

Анна Борисовна Кашина является молодым автором, произведения которого опубликованы в основном ей самой на интернет-сайте современной литературы «Самиздат» ${ }^{2}$. Среди нескольких ее текстов различных видов и жанров отличилась пьеса Дума (версия для чтения), вошедшая в 2008 году в шорт-лист литературной премии «Дебют», присуждаемой молодым авторам литературных произведений на русском языке. В 2009 году пьеса А. Кашиной была представлена на фестивале молодой драматургии «Любимовка».

Спустя два года после написания пьесы, в 2010 году А. Кашина разместила на сайте «Самиздат» новую версию произведения с подзаголовком Пьеса в двух частях. В новом тексте автор совершила ряд существенных изменений на уровнях изображенного мира, композиции и структуры, таких как: внесение в текст пьесы списка действующих лиц, изменение системы персонажей (отказ от некоторых из них и введение новых), введение имен действующих лиц перед каждой из реплик, внесение в ремарки описаний видеопроекций, сопровождающих действие пьесы, полное изменение хода событий во второй части пьесы и т. д. Именно вторая версия произведения стала объектом нашего научного интереса в силу богатства использованных в ней драматургических приемов, а также способа взаимодействия в рамках одной пьесы авторских решений, черпающих из драматургической традиции, с приемами типичными для современного мультимедийного театра.

\footnotetext{
${ }^{1}$ Несмотря на тот факт, что большая часть адресатов современной драматургии знакомится с пьесами посредством театра, затрагивая вопрос восприятия пьесы, будем обращаться к категории читателя, поскольку предметом нашего научного интереса является драма как явление литературное, не театральное.

${ }^{2}$ См.: [электронный ресурс] http://samlib.ru/k/kashina_anna_borisowna/ [19.08.2018].
} 
Стоит заметить, что в процессе работы над настоящей статьей нам не удалось найти ни одного научного исследования или критического текста, касающегося творчества А. Кашиной. Единственным обнаруженным нами упоминанием об авторе является краткое суждение о форме пьесы Дума в посте, описывающем впечатления от фестиваля «Любимовка» 2009 года, размещенном в Интернете одним из пользователей сервиса «Живой журнал» (анг. «LiveJournal») $^{3}$

Произведение А. Кашиной представляет собой ряд сцен из жизни сотрудников Государственной думы Российской Федерации. Одной из ведущих тем произведения являются отношения между депутатами и их помощниками: молодой, неопытной Анастасией, только начинающей работу в думе, молодым карьеристом Ильей и сорокалетней, преданной своей работе Маргарет.

Действие пьесы открывается монологом Ведущего - персонажа, вызывающего ассоциацию с древней драматургической традицией. Роль Ведущего схожа с функциями хора в древнегреческой драме, поскольку реплики персонажа, так же как хоровые партии, являются, в большинстве своем, комментариями происходящего на сцене ${ }^{4}$, а сам Ведущий - это одно из действующих лиц, образ которого воплощается не в совершаемых им действиях, а в произносимых им монологах.

О функции хора как действующего лица рассуждал еще Аристотель, утверждая, что хоровые песни по своему содержанию должны вписываться в фабулу, а сам хор нужно воспринимать как одного из актеров ${ }^{5}$. Несмотря на активность хора в раскрытии действия следует помнить о том, что отведенная ему роль предусматривает определенную дистанцию по отношению к происходящему на сцене:

Непосредственное участие хора в действии ограничивается репликами, имеющими характер оценки, совета, увещевания и часто принимающими форму сентенции в риторической функции убеждения, свидетельствующей об активной позиции персонажа 6 .

Ведущий в пьесе А. Кашиной, так же как античный хор, не участвует в действии непосредственно и не вступает в диалог с другими персонажами.

${ }^{3}$ См.: [электронный ресурс] https://ajushka.livejournal.com/1104122.html [20.08.2018].

${ }^{4}$ О. В. Кулишова, ХОР (др.-греч. хоро́ৎ, лат. chorus) в древнегреческом театре, [электронный ресурс] https://w.histrf.ru/articles/article/show/khor_dr_ghriech_khoros_lat_choruS_v_drievnieghriechieskoi_dramie [20.08.2018].

${ }^{5}$ Аристотель, Поэтика [в:] он же, Риторика. Поэтика, Москва: Издательство АСТ 2018, c. 325.

${ }^{6}$ Я. Л. Забудская, Функииональное значение хора в жанровой структуре греческой трагедии. Автореферат диссертации на соискание ученой степени кандидата филологических наук, [электронный ресурс] http://librarius-narod.ru/autor/zabud.pdf [20.08.2018]. 
Это действующее лицо выполняет ряд особых функций, например вводит читателя в контекст событий:

Ведущий:

Ну и как принято в каждой уважающей себя организации, неважно государственной или частной, здесь имеется свой отдел кадров. Отдел кадров Государственной Думы располагается на втором этаже старого здания $[\ldots]^{7}$,

дает характеристики действующих лиц и оценки их поведения: «Ведущий: Федор Захарович - умный, постоянно думающий и что-то планирующий, очень энергичный чиновник и невероятно нетерпеливый человек» ${ }^{8}$, а также комментирует происходящее, при этом порой намекая на свою роль в раскрытии действия:

Ведущий:

Продолжать еще можно бесконечно, но вот именно так кипит работа на седьмом этаже в кабинете депутата Крупнова. Будем надеяться, что Анастасия поднаберется опыта и помирится с Ильей. Пожелаем ей благосклонного отношения со стороны начальника и терпения всем троим: Федору Захаровичу, Илье и Насте'.

Яна Забудская в работе Функииональное значение хора в жанровой структуре греческой трагедии замечает, что в сознательном выделении лирического элемента (песен хора) могло отразиться, в том числе, и зарождение «драмы для чтения» как литературной концепции ${ }^{10}$. Генезис персонажа Ведущего в пьесе А. Кашиной частично подтверждает вышеуказанное предположение, поскольку реплики Ведущего в первоначальной версии произведения (пьесе для чтения) принадлежали неопределенному драматическому субъекту, являясь, однако, не лирическими, а повествовательными отступлениями от диалога персонажей. Ведущий таким образом становится не только персонажем подобным по своим функциям античному хору, но также приобретает черты повествователя. О повествовательной функции Ведущего могут свидетельствовать не только вложенные в его уста развернутые характеристики персонажей, но также описания места и времени действия, напр.:

${ }^{7}$ А. Б. Кашина, Дума. Пьеса в двух частях, [электронный pecypc] http://samlib.ru/k/kashina_anna_borisowna/duma.shtml [20.08.2018].

${ }^{8}$ Там же.

${ }^{9}$ Там же.

${ }^{10}$ Я. Л. Забудская, Функииональное значение..., [20.08.2018]. 
Ведущий:

Хорошее это время - лето 2007! Все вокруг благоухает, кружится, цветет и заливается красками радуги, переливаясь при солнечном свете.

Ведущий:

Ну а теперь можно заглянуть в Комитет по культуре [...] Для этого нам надо спуститься вниз и перейти по длинному стеклянному коридору в старое здание, уже там подняться на лифте на девятый этаж и, если стоять спиной к орлу, уйти немного влево ${ }^{11}$.

Положение о персонаже-повествователе в пьесе А. Кашиной входит в противоречие с достижениями теоретической поэтики, согласно которой драма является ненарративным литературным родом, а "развернутое повествовательно-описательное изображение в драме отсутствует» ${ }^{12}$. Вопросы о нарушении «ненарративности» драмы возникли в XX веке вместе с теорией эпического театра Бертольда Брехта ${ }^{13}$. Б. Брехт, вводя в свои пьесы зонги - эстрадные песни, разрушающие непрерывность действия, заявил о возможности выхода за границы иллюзорного действия и превращения персонажа из объекта в субъект истории, то есть в частицу повествования ${ }^{14}$. Ведущий в пьесе А. Кашиной перенимает часть функций повествователя, а его монологи останавливают происходящие на сцене ситуации, отодвигая его за рамки изображаемого действия. Он разрушает сценическую границу, обращаясь непосредственно к читателю и рефлексируя над произносимыми им словами, что, в свою очередь, повышает уровень метатекстуальности его высказываний.

Ведущий:

[...] В общем, мы наконец подошли к кабинету первого заместителя Председателя Комитета по культуре Барона Августина Иосифовича. Наши разглагольствования уже порядком надоели читателю и он наверняка хочет увидеть все своими глазами. Не будем больше заставлять его ждать ${ }^{15}$.

\section{${ }^{11}$ А. Б. Кашина, Дума..., [20.08.2018].}

${ }^{12}$ В. Е. Хализев, Драма, [в:] Введение в титературоведение, под ред. Л. В. Чернец, Москва: Высшая школа 2000, с. 87.

${ }^{13}$ Как замечает Н. С. Скороход в работе Брехт и эпический опыт русской сцены, в российском театре некоторые поиски в области театра «эпической формы» и очертания сценического повествования появились еще в начале XX века в спектаклях Владимира Немировича-Данченко (Братья Карамазовы 1910 г. и Воскресение 1930 г.).

${ }^{14}$ Н. С. Скороход, Брехт и эпический опыт русской сиены, «Вестник Самарского университета. История, педагогика, филология» 2016, № 1, с. 138.

${ }^{15}$ А. Б. Кашина, Дума..., [20.08.2018]. 
Говоря об отсылках к литературной традиции, содержащихся в образе Ведущего, стоит упомянуть, что на базовом уровне восприятия пьесы данный персонаж вызывает ассоциации не столько с классическими произведениями мировой словесности, сколько с современной массовой культурой, поскольку способ построения его высказываний автор заимствует у ведущих телевизионных передач о путешествиях.

Ведущий:

[...] Главной достопримечательностью столицы по-прежнему является Кремль, где с утра до позднего вечера гуляют туристы, продаются матрешки, меховые шапки и красные платки. [...] Если Вы стоите на Тверской улице, то вам открывается уникальный вид на Красную площадь, гостиницу «Националь» и Государственную Думу - законодательную власть» ${ }^{16}$.

Игра с драматургической традицией в образе Ведущего состоит в сочетании телевизионных штампов с отсылками к драматургическому опыту прошлых веков. Данное сочетание помогает создать многогранный персонаж, появления которого организуют композицию пьесы и облегчают автору задачи раскрытия характеров действующих лиц и вовлечения читателя в контекст развертывающихся перед ним событий.

Существенным элементом композиции пьесы являются ремарки с подробным описанием проекций, появляющихся на установленном на заднем фоне сцены экране. Экран как элемент сценографии усиливает изобразительный характер происходящего на сцене. Это усиление происходит за счет использования художественных средств кинематографа.

История взаимодействия театра и кино уходит корнями к экспериментам 1911-1927 годов и связана с фамилиями Лои Фулле, Винзора МакКея (Америка), Валентины де Сен-Пуа, Хораса Голдина, Поля Клоделя (Франция), Эрвина Пискатора (Германия), Сергея Эйзенштейна (СССР) а также кабаре и мюзик-холл-перформансами 20-х и художественной практикой русских футуристических перформанс-групп ${ }^{17}$. Функции проекций в пьесе А. Кашиной перекликаются с игрой с границами сценического пространства, использованной С. Эйзенштейном в спектакле Мудреи, по комедии А. С. Островского На всякого мудрец а довольно простоты (1923 г.), в который благодаря кинофельетону Дневник Глумова была включена уличная

${ }^{16}$ Там же.

${ }^{17}$ Более подробно историю взаимодействия театра и кино описывает Елена Шевченко в статье Проекиия как форма интерпретации драматического текста (на примере театров Республики Татарстан), «Вестник Челябинского государственного педагогического университета» 2017, № 1, с. 174-178. 
сцена, продолжающая действие спектакля. Проекции в пьесе А. Кашиной так же, как в спектакле С. Эйзенштейна отображают действие, происходящее вне сцены, но, кроме того, выполняют еще другие задачи: показывают мысли и фантазии персонажей, а также дополняют и иллюстрируют их высказывания. Стоит при этом заметить, что содержащиеся в ремарках описания проекций учитывают способы съемки и монтажа видеоматериала.

На экране мы видим: голубое небо с небольшим количеством облаков, полет птиц, панораму летней и солнечной Москвы с высоты птичьего полета. [...] Далее Кремль, туристы, здание Гума снаружи и изнутри [...] Затем мы видим герб России [...]. Постепенно герб становится меньше [здесь и далее полужирный шрифт мой - П. С.-К.], и мы видим само здание Государственной Думы - представительское и монолитное, сталинской постройки.

На экране появляется изображение Федора Захаровича, который после разговора с Анастасией кладет трубку, всем наигранно улыбается и жмет руку соседу по столу, показывая на часы. После, встает и выходит из зала. Заходит в другой кабинет, где ему передают пакет с документами с надписью во весь экран - СОВЕРШЕННО СЕКРЕТНО ${ }^{18}$.

Приведенные выше примеры ремарок являются очередным проявлением игрового подхода к драматургической традиции. Ремарки в пьесе Дума выполняют, кроме сложившихся со времен средневековья до XX века функций, таких как, в частности, организация сценического действия, пояснение интенций героев или выражение авторской позиции ${ }^{19}$, еще одну задачу: они являются мини-сценариями видеопроекций, введенных драматургом в сценическое пространство. Описания проекций в тексте пьесы, являющиеся непосредственным результатом использования современных технологий в театре и черпающие из поэтики киносценариев, заявляют о возможном направлении в поисках и развитии нового драматургического языка.

Помимо видеопроекций, еще одним способом расширения сценического пространства в пьесе является перенос действия в зрительный зал. Об использовании данного приема читатель узнает из первой ремарки, следующей за списком действующих лиц.

${ }^{18}$ А. Б. Кашина, Дума..., [20.08.2018].

${ }^{19}$ Больше о функциях ремарок в тексте драмы см. в работах: В. Калмыкова, Ремарка, [в:] Литературный словарь, под ред. А. В. Безрукова, Москва: Литературная учеба 2007, с. 202-204; Н. И. Ищук-Фадеева, Ремарка как знак театральной системы. К постановке проблемы, [в:] Драма и театр. Сб. науч. тр., Тверь: Тверской государственный университет 2001, с. 5-16; Н. А. Николина, Филологический анализ текста. Учебное пособие, [электронный pecypc] https://librolife.ru/g4293472 [20.08.2018]. 
[...] На заднем фоне висит экран, на котором во время монолога ведущего и по ходу пьесы время от времени появляются герои и отображается действие, параллельно происходящее вне сцены. Герои пьесы могут также появляться и в зрительном зале ${ }^{20}$.

Несмотря на то, что актеры появляются в пространстве, предназначенном для зрителей, в момент их выхода в зал сценическое действие не прерывается, а реплики персонажей не направляются к зрителям. Примечательно, что единственными моментами ломки традиционной «четвертой стены» являются монологи Ведущего, направленные, однако, не к зрителю, а к читателю ${ }^{21}$ (смотри приведенную нами выше цитату: «Наши разглагольствования уже порядком надоели читателю и он наверняка хочет увидеть все своими глазами ${ }^{22}$ »). При всей своей своеобразной роли в раскрытии действия Ведущий, согласно авторским указаниям, ни разу не переступает рампу, оставаясь при этом единственным посредником между адресатом пьесы и ее персонажами.

Последним, на что мы обратили внимание, является композиция пьесы. Автор в подзаголовке атрибутирует произведение как «пьесу в двух частях», сигнализируя отказ от традиционного жанрового определения и деления на действия и сцены. На самом деле пьеса состоит не только из указанных в подзаголовке двух частей, но также из эпилога, в котором действие переносится попеременно, то в здание Государственной думы, то в ресторан в городе Чекалин, где в ходе событий оказалась часть персонажей. Включение в композицию пьесы эпилога, служащего закреплению финальной расстановки сил и подведению нравственно-философского итога произведения ${ }^{23}$, очередной раз отсылает читателя к древнегреческой драме. Данный канонический элемент, вмонтированный в пьесу с нетрадиционной структурой, оказывается, однако, лишь формальным решением и не свидетельствует о подражании классическим образцам.

Некоторая хаотичность структуры эпилога в пьесе А. Кашиной может озадачить даже самого опытного читателя. Во-первых, в эпилоге появляется ряд персонажей, не включенных в список действующих лиц, во-вторых, примерно со своей середины эпилог начинает делиться на эпизоды, обозначенные номерами от «66» до «71». Композиционный хаос, намечаемый

\footnotetext{
${ }^{20}$ А. Кашина, Дума..., [20.08.2018].

${ }^{21}$ Трудно однозначно объяснить, почему в пьесе, которая по своему наполнению функциональными элементами сближается со сценарием, один из персонажей обращается к читателю, а не зрителю. Предполагаем, что данный фрагмент мог возникнуть в результате авторской ошибки при переписывании текста из одного варианта в другой.

${ }^{22}$ А. Кашина, Дума..., [20.08.2018].

${ }^{23}$ Цит. по: С. Страшнов, Пролог и эпилог, [в:] Литературный словарь, под ред. А. В. Безрукова, Москва: Литературная учеба 2007, с. 187.
} 
в данном фрагменте пьесы, по нашему мнению, порождает не только размышления над методами построения новейших драматургических произведений, но также вопрос о качестве редактирования текстов, публикуемых в Интернете.

На основании изложенных нами наблюдений можно сделать вывод, что суть игры с драматургическими традициями в пьесе Дума заключается в отношении к опыту предшественников как набору инструментов, из которого автор достает нужный ему элемент и вставляет его в свой текст, лишь частично соблюдая предусмотренное традицией структуральное соотношение данного элемента с другими компонентами произведения. В неполном соответствии смонтированных таким образом компонентов и заключается оригинальность новой пьесы.

\section{References}

Arystoteles, Ritorika. Poetika. Moskva: Izdatelstvo AST, 2018.

Ishchuk-Fadeeva Nina, I. Remarka kak znak teatralnoi sistemy. K postanovke problemy. In: Drama i teatr. Sbornik nauchnykh trudov, ed. I. N. Ishchuk-Fadeeva. Tver: Tverskoi gosudarstvennyi universitet, 2001: 5-16.

Khalizev Valentin, Ye. Drama. In: Vvedeniev literaturovedenie, ed. L. V. Chernets. Moskva: Vysshaya shkola, 2000: 87-93.

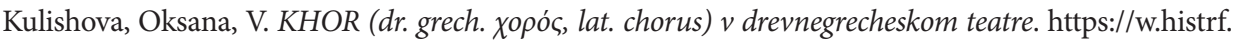
ru/articles/article/show/khor_dr_ghriech_khoros_lat_chorus_v_drievnieghriechieskoi_dramie

Literaturnyi slovar, ed. A. V. Bezrukova. Moskva: Literaturnaya ucheba, 2007.

Nikolina, Nataliya, D. Filologicheskii analiz teksta. Uchebnoe posobie. https://librolife.ru/g4293472

Shevchenko, Yelena. "Proektsiya kak forma interpretatsii dramaticheskogo teksta na primere teatrov Respubliki tatarstan”. Vestnik chelyabinskogo gosudarstvennogo pedagogicheskogo universiteta, no. 1 (2017): 174-178.

Skorokhod, Nataliya, S. "Brekht i epicheskii opyt russkoi stseny". Vestnik samarskogo universiteta. Istoriya pedagogika filologiya, no. 1 (2016): 136-141.

Zabudskaya, Yana, L. Funktsionalnoe znachenie khora $v$ zhanrovoy strukture grecheskoi tragedii. Avtoreferat dissertatsii na soiskanie uchenoi stepeni kandidata filologicheskikh nauk. Moskva, 2001. http://librarius-narod.ru/autor/zabud.pdf 